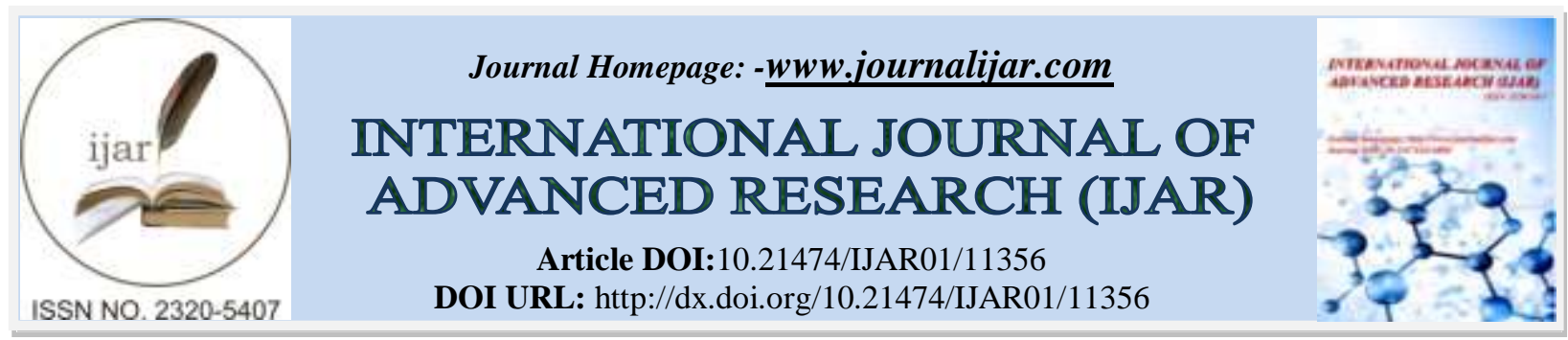

RESEARCH ARTICLE

\title{
RIGHT AND LEFT HAND MOTION ANALYSIS OF SEWING MACHINE OPERATOR
}

\section{Mohit Soni ${ }^{1}$ and Dr. Prabir Jana ${ }^{2}$}

1. Masters in Fashion Technology, Department of Fashion Technology, National Institute of Fashion Technology, New Delhi, India.

2. Doctorate in Philosophy, Department of Fashion Technology, National Institute of Fashion Technology, New Delhi, India.

\section{Manuscript Info}

\section{Manuscript History}

Received: 20 May 2020

Final Accepted: 24 June 2020

Published: July 2020

\section{Key words:-}

Human Motion Analysis, Ergonomics, Principles of Motion Economy, Sewing Operator, Tracker, Two Handed Process Chart, Five Point Analysis, MODAPTS.

\begin{abstract}
Textile and Apparel Industry second largest employment generation sector, after agriculture gives a safe place to work as compared to other manufacturing industries. But hazards and injuries faced by operators here are not fatal immediate but subtle and grow with period of time. Repetitive motions with high frequency make sewing operations ergonomic vulnerable. In this study the authors have focussed on left and right hand motions of sewing operators. Selected six different operations based on type of operation and number of plies to be attached. With the help of markers specific body parts distinguished with other body parts. Digital Camera used for capturing videos. Data Analysis (Human motion Tracking and Simulation) done by open source physics available software named Tracker. With the help of Autotracker feature of software all motions of body part analysed in every frame of video. Graph and table plotted for the x-position, yposition with respect to time. Principles of Motion economy given by International Labour Organisation (ILO, Geneva) are also verified in this paper. After analysing results and calculating distance travelled, different statements concluded like left hand moves more than right hand. Left hand never crosses needle point but right hand crosses. All pivots of hand move in synchronise with each other just the magnitude varies, finger with most movement and shoulder with lowest.
\end{abstract}

Copy Right, IJAR, 2020,. All rights reserved.

\section{Introduction:-}

The clothing industry is generally seen as a safe place to work. Compared to other industries, there are relatively few serious accidents in clothing plants. The hazards we face are different. The major health risks in this industry do not arise from immediate, potentially fatal hazards. Instead, the risks that clothing workers face come from more subtle hazards whose effect accumulates over time. Research shows that sewing machine operators face a substantially higher risk of muscle pain and injury than workers in other jobs. Studies also show that the frequency of persistent neck and shoulder injuries increases with years of employment. One report found that sewing machine operators experience as many cases of repetitive strain injuries as data entry keyers and secretaries combined. These injuries lead to long-term health effects. (Gunning, et al., 2001)

\section{Corresponding Author:- Mohit Soni}

Address: - Masters in Fashion Technology, Department of Fashion Technology, National Institute of Fashion Technology, New Delhi, India. 
As per Principles of Motion Economy, there are some sets of human body motions. They are:

1. The two hands should begin and complete their movements at the same time.

2. The two hands should not be idle at the same time except during periods of rest.

3. Motions of the arms should be symmetrical and in opposite directions and should be made simultaneously.

4. Hand and body motions should be made at the lowest classification at which it is possible to do the work satisfactorily.

5. Momentum should be employed to help the worker, but should be reduced to a minimum whenever it has to be overcome by muscular effort.

6. Continuous curved movements are to be preferred to straight-line motions involving sudden and sharp changes in direction.

7. "Ballistic" (i.e. free-swinging) movements are faster, easier and more accurate than restricted or controlled movements.

8. Rhythm is essential to the smooth and automatic performance of a repetitive operation. The work should be arranged to permit easy and natural rhythm whenever possible.

9. Work should be arranged so that eye movements are confined to a comfortable area, without the need for frequent changes of focus. (Kanawaty, 1992)
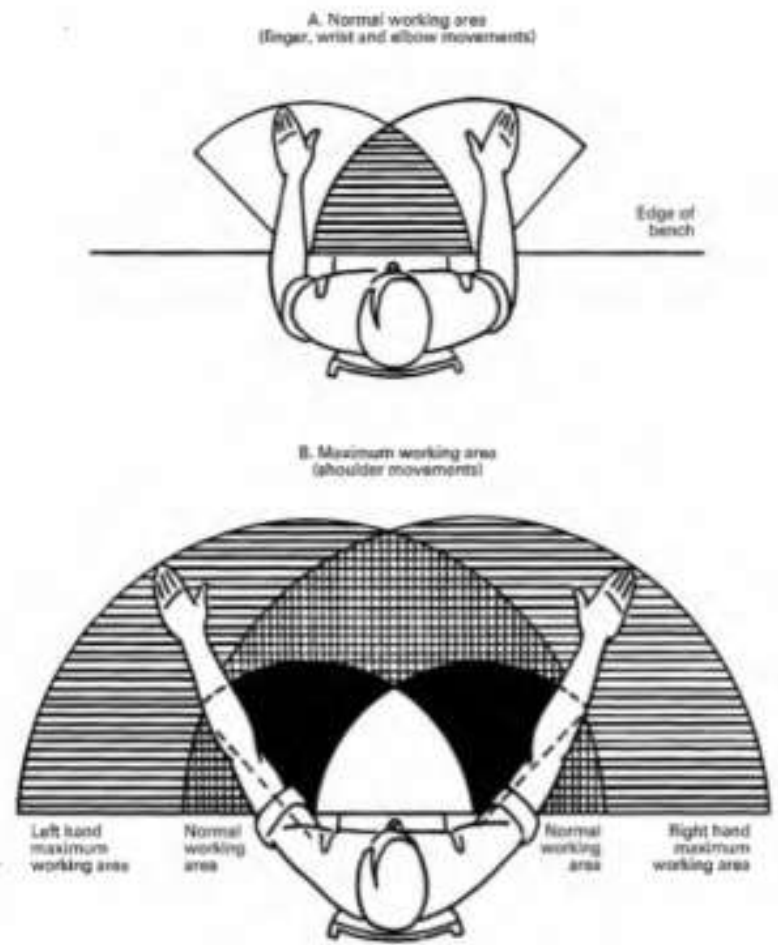

Figure 1:- Normal and Maximum Working Areas, Source ILO Geneva.

Classification of movements:

Table 1:- Classification of movements.

\begin{tabular}{|l|l|l|}
\hline Class & Pivot & Body member(s) moved \\
\hline 1 & Knuckle & Finger \\
\hline 2 & Wrist & Hand and fingers \\
\hline 3 & Elbow & Forearm, hand and fingers \\
\hline 4 & Shoulder & Upper Arm, forearm, hand and fingers \\
\hline 5 & Trunk & Torso, upper arm, forearm, hand and fingers \\
\hline
\end{tabular}

It is obvious that each movement above Class 1 will involve movements of all classes below it. Thus the saving in effort resulting from using the lowest class possible is obvious. If, in laying out the workplace, everything needed is placed within easy reach, this will minimize the class of movement which the work itself requires from the operative (Kanawaty, 1992) 


\section{Background Study:}

Ergonomics aims at preventing injuries by controlling the risk factors such as force, repetition, posture and vibration that can cause injuries to develop. Some fundamental ergonomic principals that should be followed in our workplaces are:

1. Use proper tools

2. Keep repetitive motions to a minimum

3. Avoid awkward postures

4. Use safe lifting procedures

5. Get proper rest (Gunning, et al., 2001)

\section{Two Handed Process Chart:}

The Left and Right Hand Chart is a process chart in which the activities of a worker's hands (or limbs) are recorded in their relationship to one another. It is a specialized form of process chart because it shows the two hands (and sometimes the feet) of the operative moving or static in relation to one another, usually in relation to a time scale. It is generally used for repetitive operations, when one complete cycle of the work is to be recorded.

\section{Objectives of Two Handed Process Chart:}

1. The very act of making this chart enables the work study specialist to gain an intimate knowledge of the details of the job and study each element of the job the relationships between two different activities can be established

2. The aim of this chart is to eliminate or reduce the unwanted motion to minimum

3. Give ideas for improvements and to arrange the best of motions in a possible sequence (Two Handed Process Chart)

With Two Handed Process Chart we can determine the different motions performed by right and left hand simultaneously.

\section{Human Motion Analysis and Simulation:}

Given the range of human motion related applications, there are numerous techniques that can be used to capture the human motion, to process the resulting data and also to simulate it, each one with its own strengths and weaknesses. For each application scenario it is possible to select the techniques that best fit its constraints and specific needs (e.g.: budget, scene conditions, available equipment and software, etc.).

Different available software and hardware for human motion analysis are:

Adams (http://www.mscsoftware.com/product/adams)

AnimatLab (http://www.animatlab.com)

AnyBody Modeling System (http://www.anybodytech.com)

Contemplas GmbH (Germany) (http://www.contemplas.de)

Contemplas GmbH Visual3D (http://www.c-motion.com)

BTS SMART (http://www.btsbioengineering.com)

Dartfish (http://www.dartfish.com)

DMAS: Digital Motion Analysis Suite (http://www.mi-as.com)

Hu-M-An (http://www.hma-tech.com)

KA Pro: Kinematic Analysis Software (http://userwww. sfsu.edu/biomech/ForFaculty.htm)

Kinovea (http://www.kinovea.org) 
KWON3D XP (http://www.kwon3d.com)

MaxPRO and MaxTRAQ (http://www.innovision-systems.com)

Mokka: Motion Kinematic and Kinetic Analyzer (http://b-tk.googlecode.com)

Mokka (http://www.irrd.ca/cag/mat)

MAT (Motion Analysis Tools) MotionGenesis Kane (http://www.motiongenesis.com)

MSMS: Musculoskeletal Modeling Software (http://mddf.usc.edu)

MVN Studio BIOMECH is a variant of the MVN Studio (http://www.xsens.com/ functions/human-motionmeasurement)

ODIN (http://www.codamotion.com)

OpenSim (http://opensim.stanford.edu)

SIMI Motion (http://www.simi.com)

SIMM (Software for Interactive Musculoskeletal Modeling) (http://www.musculographics.com)

Tracker 5.0.6 (https//physlets.org/tracker)

WINanalyze (http://www.mikromak.com) (Nunes, Moreira, \& Tavares, 2015)

Problem Statement:

1. To identify different motions performed by right and left hand.

2. To calculate the distance travelled by hands during different sewing operations.

3. To calculate the distance travelled by different pivots of hand.

\section{Research Methodology:-}

Select the Operations

Selection of Work to be studied on the basis of:

1. Number of plies to be attached (Operation on Single Ply, Attaching two different plies etc.)

2. Different type of machine like SNLS, Over-lock machine, Spaghetti Folder.

Depending upon the above criteria six different operations were selected and studied. They were:

1. Sleeve Attachment (Two different panels)

2. Shoulder Attachment (Two different panels)

3. Gathering (Single Ply)

4. Pocket Ready (Single Ply)

5. Serging (Over-lock machine)

6. Spaghetti Folder

\section{Record the Data:}

Obtain a digital camera. Record a video of a sewing operator:

1. Use a high contrast background.

2. Use a fluorescent neon coloured marker on the body part to be tracked (to distinguish it with background).

3. Do not move the camera while recording.

4. Make sure you have a "measurable item" in the video for calibration, like sewing table width.

5. Use a motion that is perpendicular to the camera shot. (Help)

By using markers on specific parts of hand video being captured from different angles. 
One angle perpendicular to the left side of operator (For 5-Point analysis), another angle from bird's eye view (For Left and Right Hand Motion)

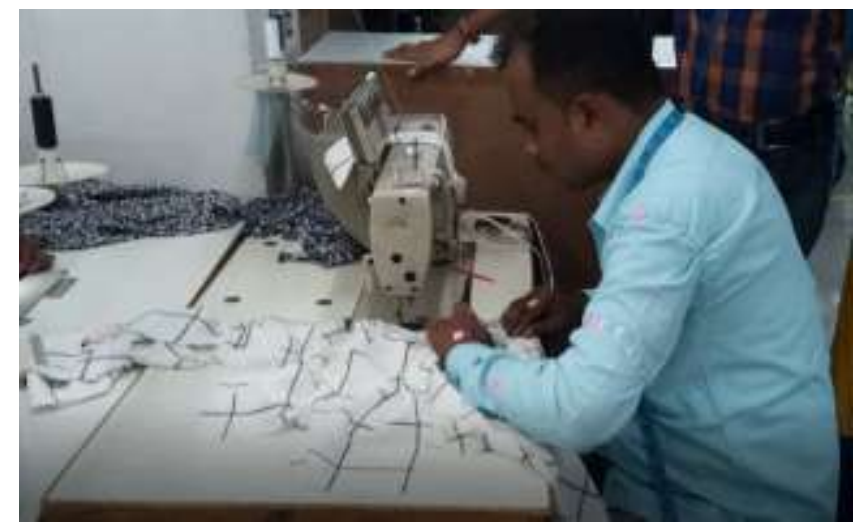

Figure 2:- Five Point Analysis.

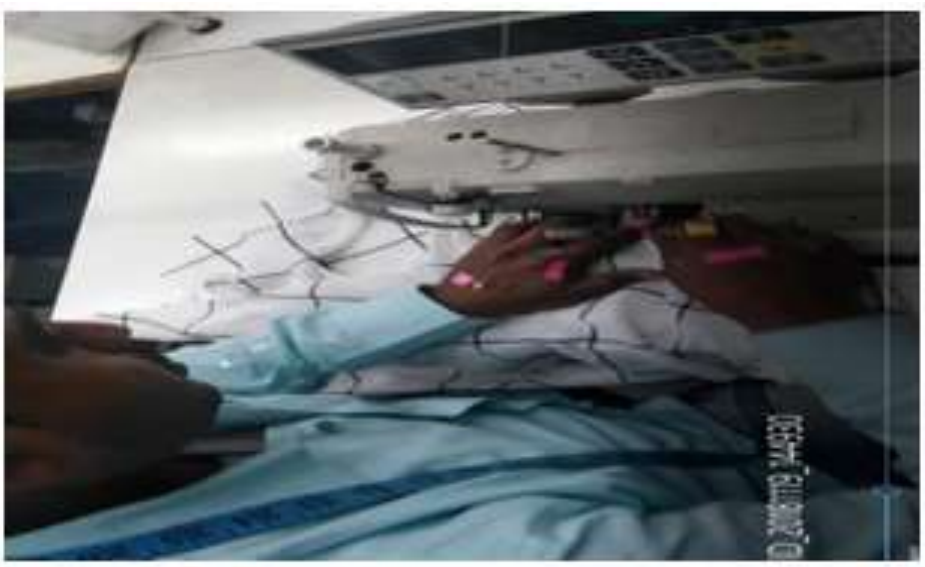

Figure 3:- Left and Right Hand Motion.

\section{Data Analysis:}

From the above exhaustive list of tools available for human motion analysis and simulation, Tracker 5.0.6 was used for analysing videos in this project.

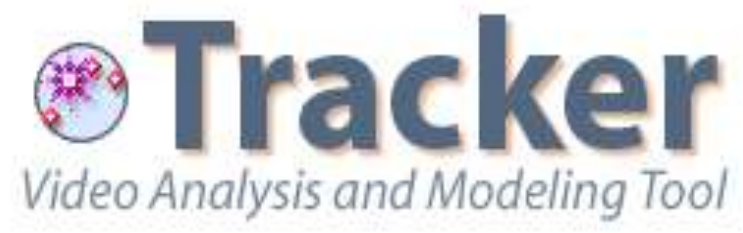

Figure 4:- Tracker Software, Source https//physlets.org/tracker.

Video captured were uploaded to Tracker, then after calibration of video frames, movement of different specific marked points was tracked by Autotracker function of this software.

Origin can be set with correspondence to sewing table length or width which was also used for calibrating video frames.

With the help of origin, different graphs, tables, plots can be plotted for different parameter such as $\mathrm{x}$-position, $\mathrm{y}$ position, displacement, velocity, acceleration, angular velocity, potential energy, kinetic energy, vector etc. with respect to frame number. 
All the available data can be extracted to excel file to calculate the distance travelled by different parts of hand during the sewing operation.

The Pythagorean Theorem provides an easy way to compute the straight line distance between any two points whose Cartesian coordinates are known. (Gutierrez)

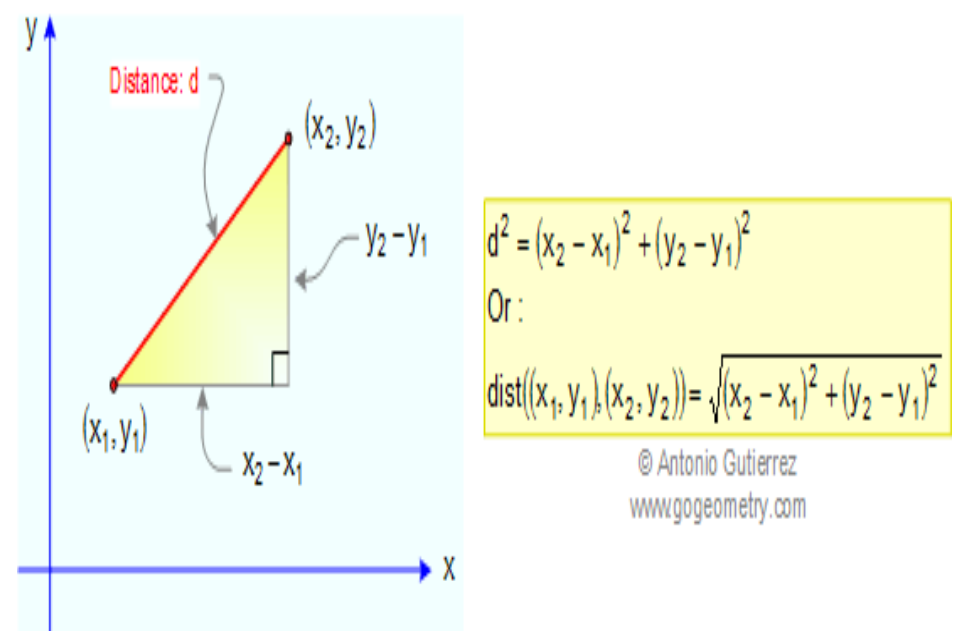

Figure 5:- Pythagoras Cartesian, Source Gogeometry.

As discussed earlier two different angles were used for capturing videos, so two different analyses were done for Left and Right Hand motion and 5-point motion analysis

\section{Left and Right Hand Motion Analysis:}

1. Two markers were pasted on the dorsal side of both left and right hand palm.

2. Video captured from the bird's eye view point.

3. After Calibration, Needle point made as the origin.

4. Through Autotracker, marked points were tracked in all frames of video.

5. Graph plotted between $\mathrm{x}$ and $\mathrm{y}$ position of movement of left hand with respect to time and compared with right hand.

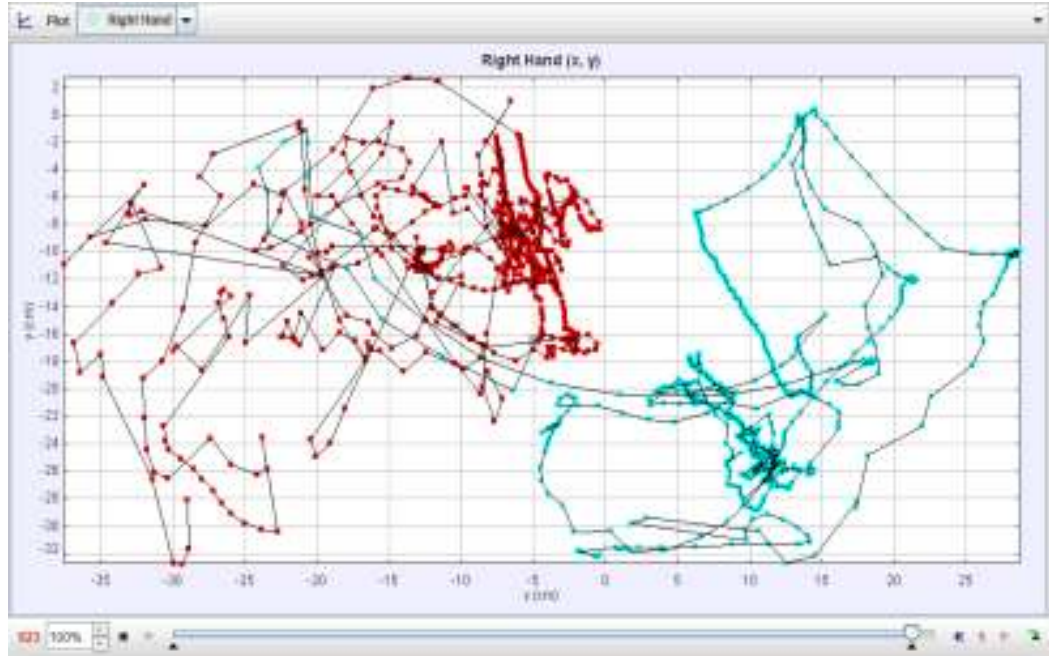

Figure 6:- Graph Left and Right Hand Motion Analysis.

All the available data extracted to excel file to calculate the distance travelled by both hands. 


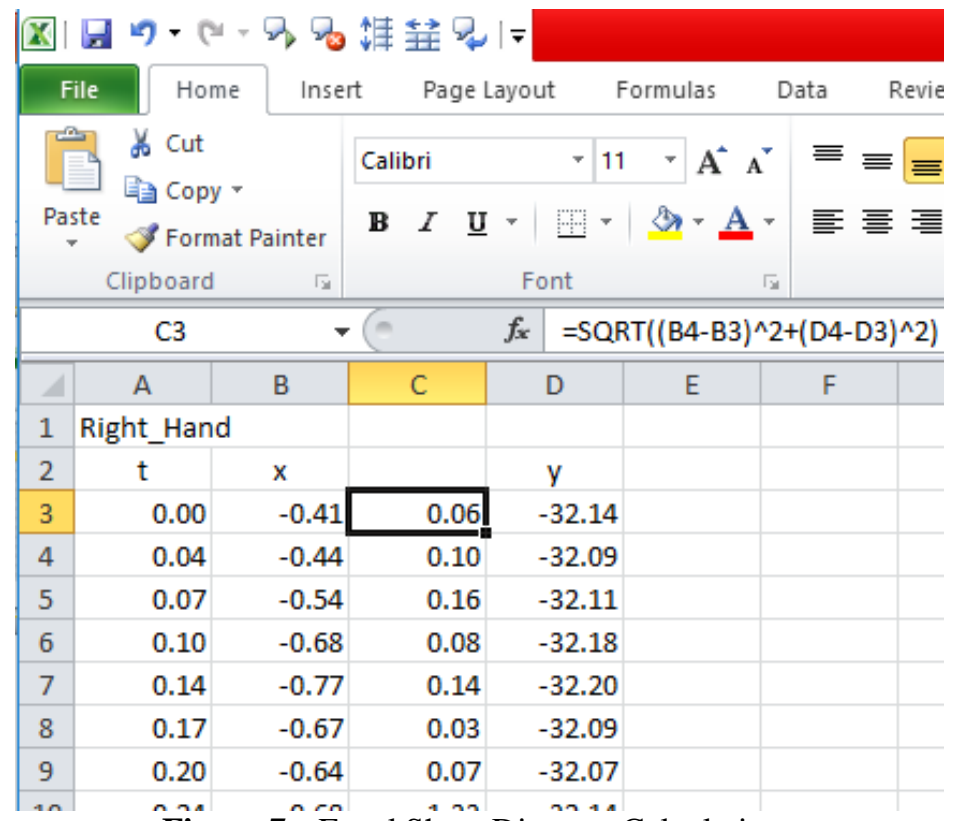

Five Point Motion Analysis:

Figure 7:- Excel Sheet Distance Calculation.

Five markers were pasted on five specific parts of left hand as per Table 1:- Classification of movements.

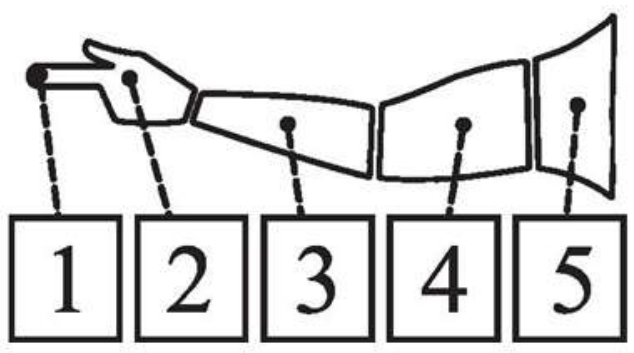

Figure 8:- Placement of Marker for Five Point Analysis.

1. Video captured at right angle from the left hand side of operator.

2. After Calibration, a portion on sewing table made as the origin.

3. Through Autotracker, marked points were tracked in all frames of video.

4. Graph plotted between $\mathrm{x}$ and y position of movement of all five points (Knuckle, Wrist, Elbow, Extended Arm, Shoulder) with respect to time.

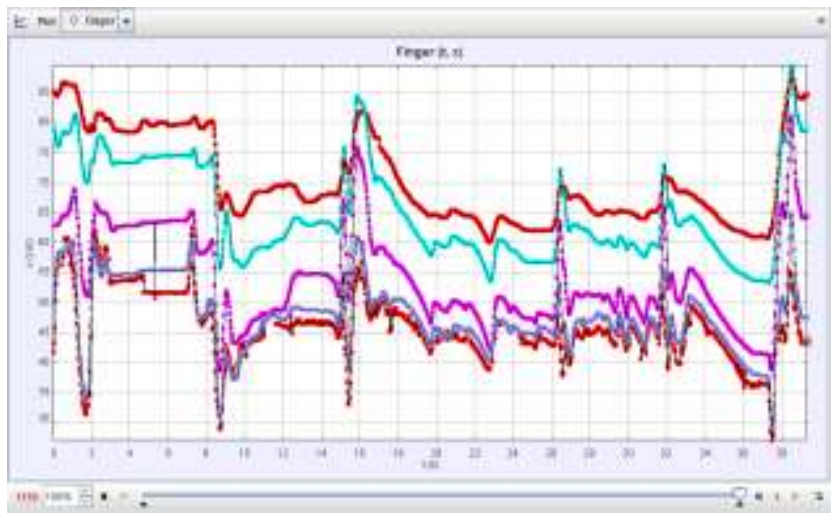

Figure 9:- Graph Five Point Motion Analysis (t, $\mathrm{x}$ ). 
All the available data extracted to excel file to calculate the distance travelled by all the five points.

\section{Principle of Motion Economy:}

The data ( $\mathrm{x}$ and $\mathrm{y}$ co-ordinates of Left Hand and Right Hand with Needle point as origin) can be used for analysis of checking for Principles of Motion Economy.

The two hands should begin and complete their movements at the same time.

The two hands should not be idle at the same time except during periods of rest.

The above two points can be checked by calculating the distance between two consecutive co-ordinates. If the coordinates of both hands are changing at the starting time and ending time that means both hand motions are beginning and terminating at the same time.

For Checking if any of the hand is idle, the consecutive co-ordinates can be checked. If the co-ordinates are same that means idle (no change).

Motions of the arms should be symmetrical and in opposite directions and should be made simultaneously.

By symmetry, it means that both hand motions should be mirror image to each other. So taking origin and $\mathrm{X}$ and $\mathrm{Y}$ Axes as mirror it can be used to analyse when both hands are coming towards origin or vice-versa.

The distance of each co-ordinate from origin can be calculated by distance formula. Then for every consecutive coordinate of Right Hand and Left Hand at same timeframe, it can be identified that distance is increasing or decreasing i.e. coming towards the origin or going forwards the origin.

If the distance is either increasing or decreasing in both the hands (condition should be same in both hands), then it is symmetrical otherwise asymmetrical (i.e. one increasing and other decreasing).

Calculation of number of points in the normal and extended reach area (i.e. the primary and the secondary area)

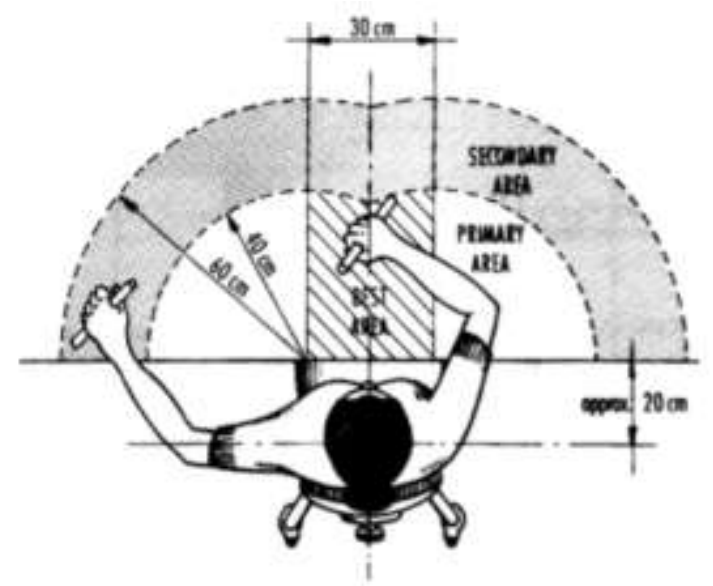

Figure 10:- Normal and Extended reach areas at table-top height for a seated small worker, Source ILO, Geneva.

As discussed earlier needle point is taken as the origin for all co-ordinates. In the above figure 10, operator is sitting at a distance of $20 \mathrm{~cm}$ from sewing table. The centre line is the stitching line and the distance of needle from table edge is taken $12 \mathrm{~cm}$ approximately.

The primary area being decided by the elbow points of both hand for left hand $(-15,-12)$ and for right hand $(15,-12)$

The distance of each Left Hand co-ordinate from Left Hand Elbow and Right Hand co-ordinate from Right Hand Elbow calculated bt distance formula. 
If the distance is more than $40 \mathrm{~cm}$ (i.e. the range of primary area) and the co-ordinates are outer the primary area range, those points were separately counted to find out how many points are outside primary range.

Results and Discussion:-

Left and Right Hand Motion Analysis

Table 2:- Distance Travelled by Left and Right Hand.

\begin{tabular}{|l|l|l|l|l|}
\hline Operation (One Cycle) & $\begin{array}{l}\text { Left Hand } \\
\text { (in cm) }\end{array}$ & $\begin{array}{l}\text { Right Hand } \\
\text { (in cm) }\end{array}$ & Difference & \%Difference \\
\hline Sleeve Attachment & 753.8 & 492.6 & 261.2 & 34.65 \\
\hline Gathering & 432.7 & 381.6 & 51.1 & 11.81 \\
\hline Pocket ready & 375.4 & 278.5 & 96.9 & 25.73 \\
\hline Serging & 979.6 & 508.1 & 471.5 & 48.14 \\
\hline Shoulder Attachment & 1010.2 & 559.2 & 450 & 44.64 \\
\hline Spaghetti Folder & 805.2 & 612.1 & 193.1 & 23.98 \\
\hline
\end{tabular}

\section{Sleeve Attachment}

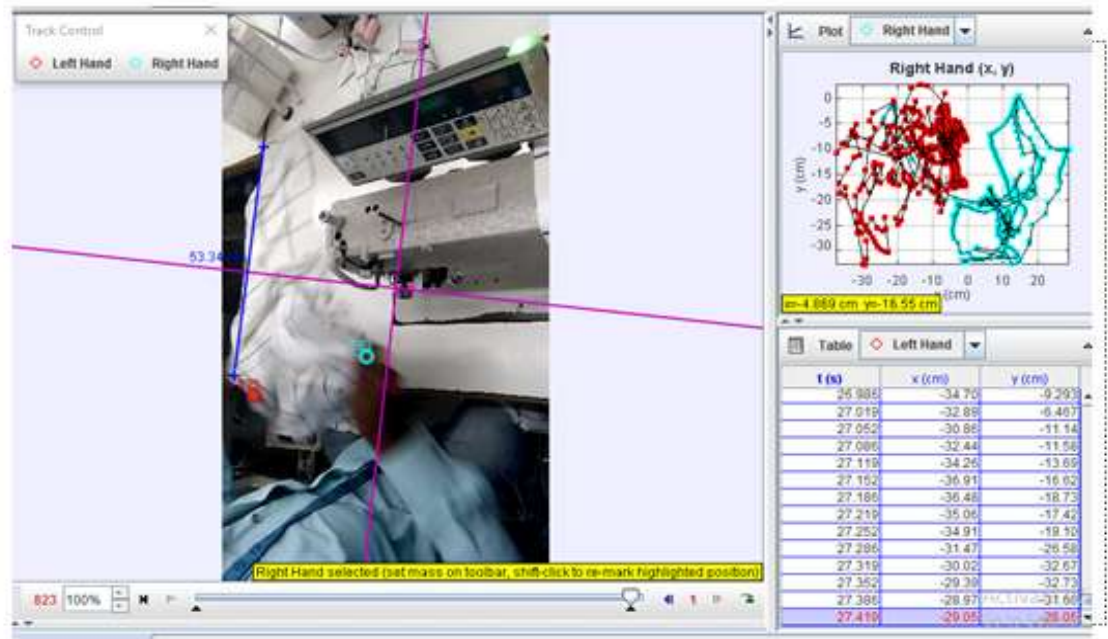

\section{Gathering}

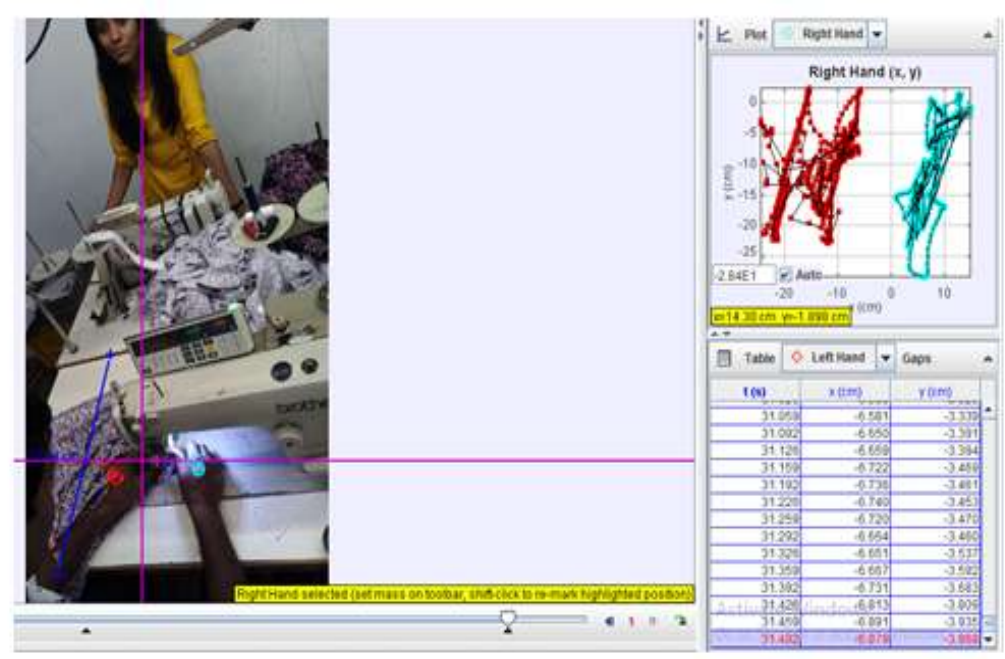


Pocket Ready

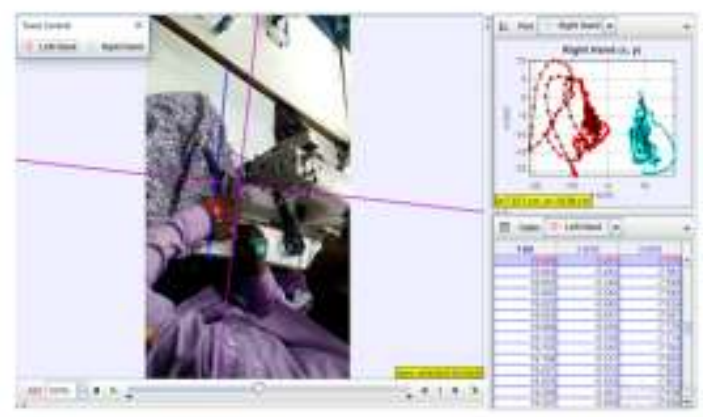

Serging

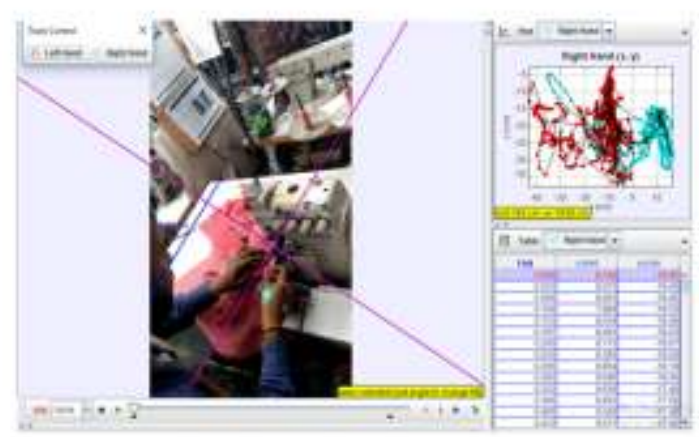

Shoulder Attachment

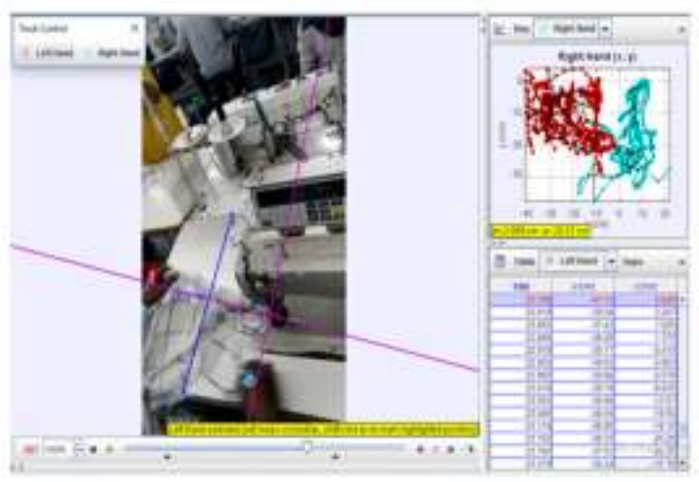

Spaghetti Folder

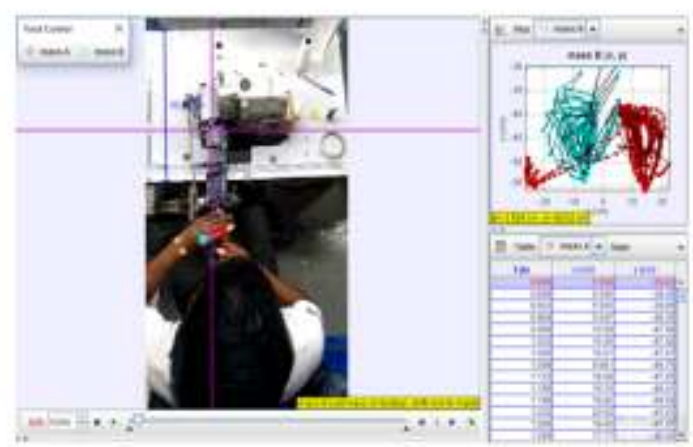


Five Point Motion Analysis:

Table 3:- Distance Travelled by Five Points.

\begin{tabular}{|l|l|l|l|l|l|l|}
\hline Operation & $($ In Cm) & Shoulder & Arm & Elbow & Wrist & Finger \\
\hline \multirow{3}{*}{$\begin{array}{l}\text { Gathering } \\
\text { Pecket }\end{array}$} & Distance & 195.15 & 341.18 & 628.22 & 775.95 & 809.97 \\
\cline { 2 - 7 } & \%Distance & 24.0 & 42.12 & 77.56 & 95.79 & 100 \\
\hline \multirow{2}{*}{ Serging } & Distance & 238.30 & 275.62 & 402.46 & 381.35 & 893.06 \\
\cline { 2 - 7 } & \%Distance & 26.68 & 30.86 & 45.06 & 42.70 & 100 \\
\hline \multirow{2}{*}{$\begin{array}{l}\text { Shoulder } \\
\text { Attach }\end{array}$} & Distance & 80.74 & 206.99 & 328.91 & 424.70 & 634.07 \\
\hline \multirow{2}{*}{$\begin{array}{l}\text { Sleeve } \\
\text { Attach }\end{array}$} & Distance & 12.73 & 32.64 & 51.87 & 66.98 & 100 \\
\cline { 2 - 7 } & \%Distance & 232.04 & 412.45 & 615.52 & 749.11 & 1101.08 \\
\cline { 2 - 7 } & Distance & 218.07 & 37.46 & 55.90 & 68.03 & 100 \\
\hline \multirow{2}{*}{} & \%istance & 18.41 & 380.79 & 554.55 & 623.83 & 1187.16 \\
\hline
\end{tabular}

Gathering

Serging

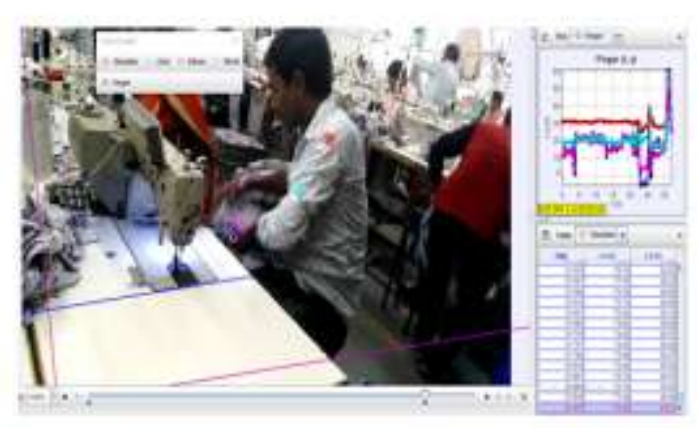

Pocket ready

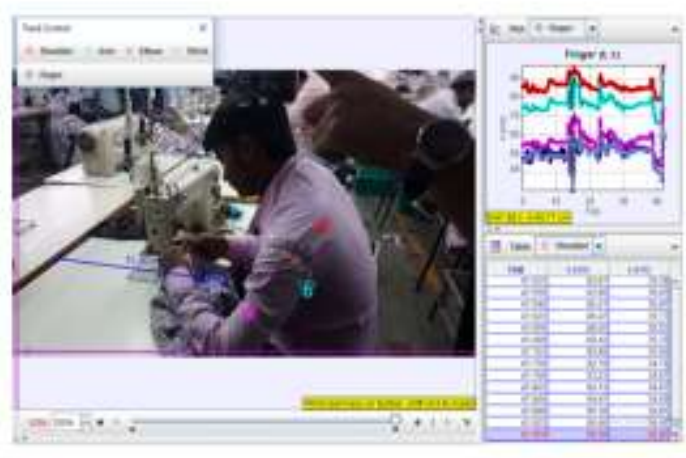

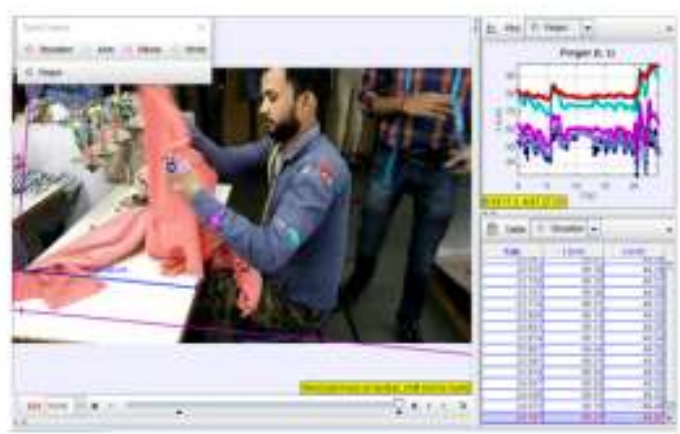

Shoulder Attachment

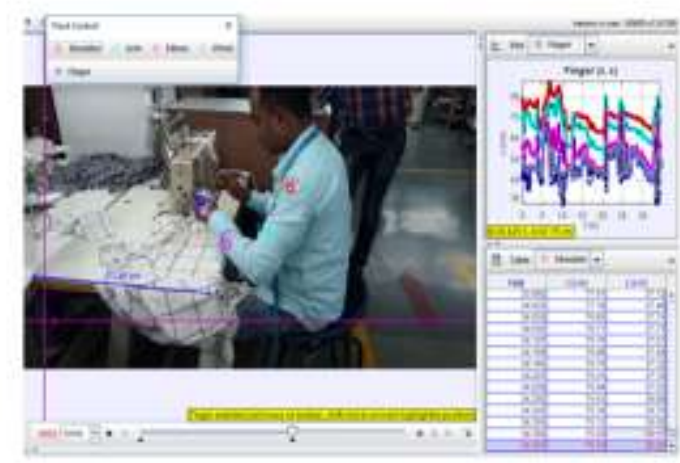

Sleeve Attachment

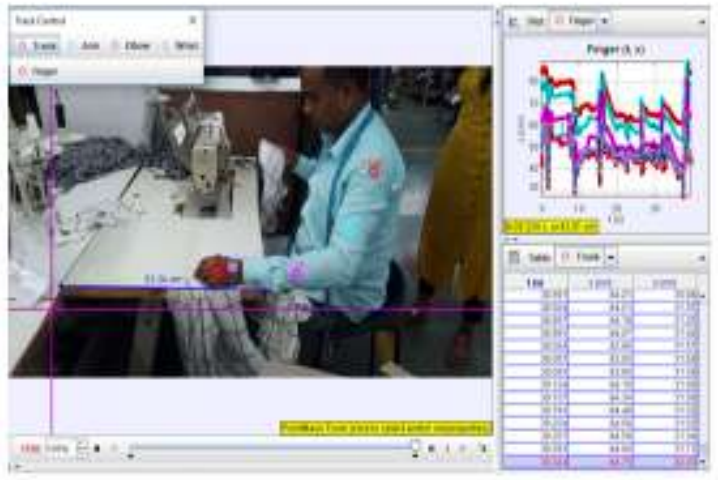




\section{Principles of Motion Economy:}

As the distance between the origin and the consecutive co-ordinates for both the hands was changing at the beginning and ending, it can be stated that in all six operations Right and Left Hand start and end moving together.

The difference between two consecutive co-ordinates was never zero in all six operations, it can be stated that both hands were not at idle position instead of rest time.

Symmetry of both hands can be identified by comparing the increasing and decreasing values of consecutive coordinates for both hands. If both are in same direction i.e. either increasing or decreasing then both hands motion is symmetrical otherwise asymmetrical.

\begin{tabular}{|l|l|l|}
\hline Operation & Symmetrical \% & Asymmetrical \% \\
\hline Sleeve Attachment & 60.27 & $39 . .73$ \\
\hline Gathering & 56.43 & 43.57 \\
\hline Pocket Ready & 54.6 & 45.4 \\
\hline Serging & 63.34 & 36.66 \\
\hline Shoulder Attachment & 56.53 & 43.47 \\
\hline
\end{tabular}

Table 4:- Symmetrical and Asymmetrical Motions.

Primary and secondary working area being defined by $40 \mathrm{~cm}$ and $60 \mathrm{~cm}$ respectively. (Hiba \& Bheda)

The number of points outside the primary area was calculated by defining the centre and radius of the primary area and distance of each co-ordinate with respect to centre of primary area.

Table 5:- Motions in Primary Axis.

\begin{tabular}{|l|l|l|}
\hline Operation Name & Left Hand in Primary Area & Right Hand in Primary Area \\
\hline Sleeve Attach & $100 \%$ & $100 \%$ \\
\hline Gathering & $100 \%$ & $100 \%$ \\
\hline Pocket Ready & $100 \%$ & $100 \%$ \\
\hline Serging & $100 \%$ & $98 \%$ \\
\hline Shoulder Attachment & $100 \%$ & $100 \%$ \\
\hline
\end{tabular}

Only in Serging Right Hand moves out of the Primary Area for 2\%.

\section{Conclusion:-}

\section{Left and Right Hand Motion Analysis:}

1. Left hand movement $>$ Right hand movement

2. \% of movement difference varies from Operation to Operation

3. In all Operations, Right Hand crosses the Needle point whereas Left Hand doesn't cross needle point

4. Only in case of Spaghetti both Right and Left hand cross the needle point and move towards opposite direction

\section{Five Point Motion Analysis:}

1. All five point movements are synchronised with respect to time but their magnitude varies

2. The difference between hand motion of different body parts can be easily calculated

3. In all sitting operations, distance travelled by finger is highest and distance travelled by shoulder is lowest.

4. \% of movement difference between shoulder and finger varies from Operation to Operation

\section{Future Scope of Study:-}

1. More Operations can be studied to find out more accurate relation between percentage difference of Left and Right Hand Motion.

2. Study can be taken forward for different bed types of sewing machine like post bed, cylindrical bed and hand motions can be tracked and analysed.

3. Validation of the point that Right Hand crosses Needle Point but Left Hand doesn't cross can be done by taking more samples. 
4. This software and method can be used for calculating difference between standing and sitting operations (For Example if a same operation can be performed standing and sitting, which is more accurate ergonomically can be identified)

5. Not only sewing operations, but other operations in Cutting and Finishing Department can also be analysed.

6. Can be used for designing ergonomic work station as per minimum movements of five points.

7. The Five Point Motion Analysis can be used for MODAPTS.

8. MODAPTS stand for MODular Arrangement of Pre-determined Time Standards.

9. It differ from others as it focus on the body part doing the moving rather than the distance covered by the body part of the object being handle.

10. Just the distance travelled by different parts calculated and is multiplied to the respective code (Jana \& Tiwari, 2018)

\section{Reference:-}

1. Gunning, J., Eaton, J., Ferrier, S., Frumin, E., Kerr, M., King, A., et al. (2001). Ergonomic handbook for the Clothing Industry. Union of Needletrades, Industrial and Textile Employees, the Institute for Work \& Health, and the Occupational Health Clinics for Ontario Workers, Inc.

2. Gutierrez, A. (n.d.). go geometry . Retrieved December 21, 2018, from Land of The Incas: http://gogeometry.com/pythagoras/right_triangle_formulas_facts.htm

3. Help, T. (n.d.). Tracker Help. Retrieved December 21, 2018, from Tracker 5.0: https://physlets.org/tracker/help/frameset.html

4. Hiba, J. C., \& Bheda, R. (n.d.). Improving Working Conditions and Productivity in the Garment Industry. Geneva: International Labour Office, Geneva.

5. Jana, P., \& Tiwari, M. (2018). Industrial Engineering in Apparel Manufacturing. New Delhi: Apparel Resources Publication.

6. Kanawaty, G. (1992). Introduction to Work Study (Fourth Edition). Geneva: International Labour Office Geneva.

7. Nunes, J. F., Moreira, P. M., \& Tavares, J. M. (2015, September). Human Motion Analysis and Simulation Tools: A Survey. ResearchGate, p. 32.

8. Two Handed Process Chart. (n.d.). Retrieved December 21, 2018, from LEFT HAND-RIGHT HAND CHART (Two-handed Process Chart: http://fac.ksu.edu.sa/sites/default/files/left_hand-right_hand_chart_twohanded_process_chart.pdf. 